\title{
JORNALISMO LITERÁRIO DE VIAGEM INTERNACIONAL: UM PANORAMA DO CENÁRIO AUTORAL BRASILEIRO
}

\author{
Literary journalism about international travel: a panorama of the brazilian \\ scenario
Periodismo literario de viaje internacional: un panorama del escenario brasileño

Eduardo Ritter Professor Adjunto da Universidade Federal de Santa Maria (UFSM), campus Frederico Westphalen rittergaucho@hotmail.com

\section{Resumo}

Um dos genêros literários mais antigos é a narrativa de viagem. Assim como jornalistas, especialmente os que praticaram o estilo que ficou conhecido como New Journalism, trouxeram técnicas e métodos do romance ficcional para produzir os livros-reportagens, as narrativas de trânsito humano também ganharam espaço dentro do que hoje é chamado Jornalismo Literário. Destarte, a presente pesquisa compartilha o mapeamento feito apresentando o cenário de jornalistas brasileiros que relatam viagens internacionais no formato de livro. Tal levantamento, que integra o projeto de pesquisa Jornalismo Literário de Viagem: Narrativas de Jornalistas Transitando pelo Mundo, foi feito a partir da Análise de Conteúdo, de Bardin (2011) e Hercovitz (2007). Já a base teórica parte principalmente das premissas de Martinez (2016) e Lima (2004). No total, foram identificadas 60 obras do gênero produzidas por 35 jornalistas-escritores viajantes.

\section{Palavras-chave}

Jornalismo literário. Jornalismo de viagem. Jornalistas Brasileiros.

\begin{abstract}
One of the oldest literary genres is the travel narrative. Just as journalists, especially those who practiced the style that became known as New Journalism, brought techniques and methods from the fictional novel to produce the book reports, the human traffic narratives also gained space within what is now called Literary Journalism. Thus, the present research shares the mapping done presenting the scenario of Brazilian journalists reporting international travel in book format. This survey, which integrates the project Literary Journey Journalism: Narratives of Journalists Transiting the World, was made from Content Analysis, Bardin (2011) and Hercovitz (2007). The theoretical basis is based mainly on the premises of Martinez (2016) and Lima (2004). In total, 60 works of this kind were produced by 35 journalist-traveling writers.
\end{abstract}




\section{Key words}

Literary journalism. Travel Journalism. Brazilian Journalists.

\section{Resumen}

Uno de los genios literarios más antiguos es la narrativa de viaje. Así como periodistas, especialmente los que practicaron el estilo que se conoció como New Journalism, trajeron técnicas y métodos de la novela ficcional para producir los libros-reportajes, las narrativas de tránsito humano también ganaron espacio dentro de lo que hoy es llamado Periodismo Literario. De este modo, la presente investigación comparte el mapeo hecho presentando el escenario de periodistas brasileños que relatan viajes internacionales en el formato de libro. En el caso de que se produzca un cambio en la calidad de la información, se debe tener en cuenta que, La base teórica parte principalmente de las premisas de Martínez (2016) y Lima (2004). En total, se identificaron 60 obras del género producidas por 35 periodistas-escritores viajeros.

\section{Palabras clave}

Periodismo literario. Periodismo de viaje. Periodistas Brasileños.

\section{CONSIDERAÇÕES INICIAIS}

Hunter Thompson, Ernest Hemingway, George Orwell, Erico Verissimo, Euclides da Cunha, Juremir Machado da Silva, Airton Ortiz, Bruce Chatwin, Tiziano Terzani e muitos outros formam uma lista de jornalistas autores de livros de viagem que, com as publicações anuais contínuas, torna-se infindável. São jornalistas que seguem produzindo um estilo de texto milenar, pois desde Homero, poeta grego do século VIII a.C., passando Marco Polo e Pero Vaz de Caminha, até se chegar aos jornalistas contemporâneos, os relatos de trânsito pelo mundo formam um estilo literário que estão em prática há muito tempo na literatura ficcional e de não ficção.

Dessa forma, com base no conceito de relatos do trânsito humano no jornalismo de Martinez (2016) e da categoria livro-reportagem de Lima (2004) o presente artigo compartilha os primeiros resultados do trabalho desenvolvido através do projeto de pesquisa intitulado Jornalismo Literário de Viagem: Narrativas de Jornalistas Transitando pelo Mundo. No entanto, ressalta-se a importância de tal levantamento, sistematizado aqui pelo autor, pois esse é um campo vasto a ser explorado por pesquisadores do Jornalismo, principalmente do Jornalismo Literário, sendo que até o momento ainda não há o registro de tais dados no cenário acadêmico nacional.

Durante a pesquisa, inicialmente foi realizado o mapeamento de obras de jornalistas de todas as nacionalidades que publicaram livros-reportagem-viagem, conceito abordado mais 
adiante. Destarte, para o presente artigo, foram selecionadas apenas as obras de autoria de jornalistas brasileiros em trânsito. Elas foram divididas em três grandes categorias: viagens realizadas dentro do território nacional, viagens ao exterior e cobertura de guerra. Salienta-se que as duas categorias não incluídas nesse estudo, serão tema de pesquisa do grupo em outros momentos. Tem-se, então, a delimitação de nosso objeto de estudo: obras escritas por jornalistas brasileiros em viagens internacionais, excetuando relatos de guerra.

E como realizar tal investigação? O procedimento metodológico utilizado para fazer tal mapeamento foi a Análise de Conteúdo (AC), de Bardin (2011) e de Herscovitz (2007). Inicialmente ressaltamos que a $\mathrm{AC}$ é um método consagrado na área das Ciências Sociais e Humanas que se caracteriza pela utilização de inúmeras técnicas de pesquisa para investigar fenômenos simbólicos. Já empregado anteriormente em áreas como a Sociologia, o método só passou a ser usado para o estudo dos conteúdos midiáticos a partir do início do século XX: “a análise de conteúdo descreve com objetividade e precisão o que era dito sobre um determinado tema, num determinado lugar e num determinado espaço” (HERSCOVITZ, 2007, p. 123). Salienta-se a flexibilidade metodológica da AC, afinal, hoje a intenção "desfavorece a dicotomia entre o quantitativo e o qualitativo, promovendo uma integração entre as duas visões" (HERSCOVITZ, 2007, p. 126). Bardin, por sua vez, explica que a AC é "um conjunto de instrumentos cada vez mais sutis em constante aperfeiçoamento, que se aplicam a 'discursos' (conteúdos e continentes) extremamente diversificados" (BARDIN, 2011, p. 37). Dessa forma, foram elencadas três questões que envolvem categorias específicas para a elaboração do mapeamento: 1) produção jornalística: a obra foi escrita por um jornalista? 2) jornalismo: a obra é ficção ou não-ficção? 3) livro-reportagem viagem: a obra é um livro-reportagem viagem e não é cobertura de guerra? Feita essa análise prévia nas obras encontradas, pode-se elaborar o mapeamento que apresenta as obras identificadas pelos pesquisadores nessa etapa do estudo. Antes de apresentar e fazer uma reflexãoi inicial em torno de tal mapemaento, retomamos alguns conceitos básicos sobre a temática, começando pela discussão em torno do que é Jornalismo Literário até se chegar a proposta de uma conceituação do que aqui é chamado de Jornalismo Literário de Viagem.

\section{JORNALISMO LITERÁRIO: POLÊMICAS, CONCEITOS E TERMINOLOGIA}

Inicialmente, vale ressaltar que optamos pela utilização do termo Jornalismo Literário, utilizado por Martinez (2016), para definir essa prática jornalística caracterizada por ser um 
estilo narrativo no qual há uma convergência entre técnicas do Jornalismo e da Literatura. Reconhecemos a polêmica em torno da terminologia, mas entendemos que essa é uma nomenclatura já consagrada nos estudos de jornalismo. Apesar disso, mesmo considerando que tal terminologia já está consagrada, ao longo do presente artigo terminologias sobre o que chamamos aqui de Jornalismo Literário de Viagem são postas em discussão, inclusive para que haja um diálogo com outros teóricos como nominar esse tipo de prática jornalística.

Reconhece-se, no entanto, que há tanto na AC quanto no presente artigo discussões conceituais em torno de terminologias que torna os estudos de AC mais producentes na atualidade - e no próprio artigo.

Com um caráter diferenciado do jornalismo noticioso, que se caracteriza por ser sucinto, como no modelo da pirâmide invertida, e que visa o ideal da objetividade, o Jornalismo Literário se caracteriza pelos dez pilares apontados por Martinez (2016): 1) exatidão e precisão, 2) narração de história; 3) humanização; 4) compreensão; 5) universalização temática; 6) voz autoral; 7) imersão; 8) simbolismo; 9) criatividade; e 10) responsabilidade ética.

Pena (2006), por sua vez, apresenta a visão de que o Jornalismo Literário é uma alternativa para os jornalistas saírem da lógica comandada pela espetacularização, pelos interesses econômicos e pela busca da audiência. Nesse sentido, o autor define jornalismo literário como:

Significa potencializar os recursos do Jornalismo, ultrapassar os limites dos acontecimentos cotidianos, proporcionar visões amplas da realidade, exercer plenamente a cidadania, romper as correntes burocráticas do lead, evitar os definidores primários e, principalmente, garantir perenidade e profundidade aos relatos (PENA, 2006, p. 13).

A relação entre Jornalismo e Literatura, aliás, está sempre presente na vida dos jornalistas literários. Analisando a lista dos 100 autores clássicos da literatura ocidental elaborada em Guia de Leitura, de Masina (2009), observa-se que a maioria deles teve passagem por redação de jornais. Em outras palavras, praticamente todos os grandes escritores da literatura ocidental acabaram atuando em algum momento de suas vidas no jornalismo. "[...] as redações tornaram-se o lugar (quase) perfeito encontrado pelos escritores para trabalharem de forma remunerada, tanto no Brasil quanto no exterior" (RITTER, 2016a, p.19). Diversos deles se caracterizaram por serem jornalistas literários. "Difícil encontrar um escritor que não seja jornalista, e a história do jornalismo conta com múltiplas participações 
diretas de escritores, tanto na gênese do meio de comunicação como em seu desenvolvimento" (MONTORO, 1973, p. 44).

Apesar das ligações históricas que podem ser apontadas relacionando o Jornalismo e a Literatura, diversos teóricos apresentam a diferenciação dos dois gêneros. Um deles é Bulhões (2007) que defende que há um certo abismo ontológico que separa o Jornalismo da Literatura. Enquanto o Jornalismo teria como função apurar os acontecimentos, difundir informações da atualidade, captando o movimento da própria vida, visando a isenção e a imparcialidade, a Literatura teria uma natureza oposta a do Jornalismo, adotando uma linguagem verbal de uma dimensão que não é meio, mas fim. O autor destaca que a convergência entre Jornalismo e Literatura é, por natureza, um território de impasses. Destarte, o ponto essencial da confluência de gêneros entre as duas áreas é o que se refere à narratividade.

Produzir textos narrativos, ou seja, que contam uma sequência de eventos que se sucedem no tempo, é algo que inclui tanto a vivência literária quanto a jornalística. E a narratividade possui conexão estreita com a temporalidade, o que significa dizer que se contam eventos reveladores da passagem de um estado a outro. Além disso, é bom não perder de vista que a narratividade está intimamente vinculada à necessidade humana de conhecimento e revelação do mundo ou da realidade (BULHÕES, 2007, p. 40).

Já Lima (2004) e Belo (2006) chamam esse ponto de convergência entre o Jornalismo e a Literatura de livro-reportagem. Assim como Pena (2006), Belo (2006) também apresenta esse formato como uma alternativa ao jornalismo cotidiano. Comparando as condições para publicações brasileiras com as americanas, ele comenta: "Ainda sem o mesmo potencial e mesmo com as dificuldades inerentes a uma economia restrita e um mercado editorial limitado, esse tem sido um caminho promissor para os profissionais da reportagem" (BELO, 2006, p. 18).

Por fim, tem-se os autores que consideram o jornalismo literário como um gênero jornalístico. Um desses autores chega a dizer que "nesta gama de gêneros jornalísticos, o Jornalismo Literário se apresenta, com mais frequência, na grande reportagem" (BORGES, 2013, p. 77). Boynton (2005), por sua vez, defende que os jornalistas literários contemporâneos produzam livros-reportagens visando a sua consagração jornalística, e não mais literária, como ocorria com os jornalistas escritores do New Journalism dos anos 1960 e 1970. 
Diante de perspectivas diferentes, conforme ressaltado, partilhamos do argumento de Martinez (2016) e também de Cosson (2001), que mesmo utilizando outra terminologia, a de romance reportagem, considera essa prática como um gênero autônomo, afinal, como destaca o autor:

Por um lado, não é jornalismo, uma vez que é romance; por outro, não é literatura, uma vez que é reportagem. O saldo de tal ambiguidade é o fato de as narrativas assim denominadas terminar por ser lidas não no que elas são (romance-reportagem), mas naquilo que não conseguiram ser (romance ou reportagem) (COSSON, 2001, p. 9).

Dessa maneira, utiliza-se no presente artigo a perspectiva de jornalismo literário para se analisar aquilo que as obras selecionadas são: jornalismo literário de viagem.

\section{JORNALISMO LITERÁRIO DE VIAGEM: UMA PROPOSTA CONCEITUAL}

Para apresentarmos uma proposta de conceito de jornalismo literário de viagem optamos pelas perspectivas de Martinez (2016) e Lima (2004). O segundo autor apresenta uma proposta de classificação para os chamados livros-reportagem. São 13 categorias, sendo que a última delas é justamente o livro-reportagem-viagem. Conforme o autor, esse tipo de livro-reportagem tem como foco principal uma viagem a alguma região geográfica específica, "o que serve de pretexto para retratar, como em um quadro sociológico, histórico, humano, vários aspectos das realidades possíveis do local” (LIMA, 2004, p.58). O autor complementa que esse é um relato diferente do meramente turístico ou daqueles feitos por pessoas não treinadas profissionalmente para escrever. Diferentemente disso, o jornalista é um profissional que domina as técnicas da escrita, especialmente quando se trata de uma obra jornalísticoliterária.

Nesse mesmo sentido, a perspectiva de Lima (2004) é exportada ao campo do Jornalismo Literário por Martinez (2016), quando a autora aborda os relatos do trânsito humano dentro do Jornalismo. Ela salienta que após a consolidação do Jornalismo enquanto profissão a partir do século XIX, muitos jornalistas-escritores passam a publicar livros com o “excedente de seu material de reportagem ou reflexões sobre suas próprias viagens" (MARTINEZ, 2016, p.80). Porém, a autora aborda o jornalismo literário de viagem a partir de uma perspectiva aberta, ou seja, que inclui textos produzidos para jornais, revistas e outras mídias. Nesta pesquisa, o foco são as obras de jornalismo literário de viagem publicadas no formato livro. 
Para além da importância deste tipo de produção para o Jornalismo, também vale ressaltar que as narrativas de viagens escritas por jornalistas também se tornam importantes documentos históricos. Esse é um dos caráteres que tornam diversas dessas obras atemporais. Exemplo claro são as narrativas de viagem de Erico Verissimo, pois as temáticas de muitos dos seus livros giram em torno de acontecimentos históricos, sendo esse o caso, por exemplo, de A Volta do Gato Preto, pois nessa narrativa o escritor estava nos Estados Unidos justamente enquanto a Segunda Guerra Mundial se desenvolvia.

Nesse sentido, vale destacar, pois, a perspectiva de Benedeti que apresenta importante semelhança entre Jornalismo e História: "História e jornalismo aproximam-se tanto na natureza de seu objeto (a realidade) quanto no tipo de trabalho que realizam (produção de relatos fáticos)" (BENEDETI, 2009, p.67). Contudo, a autora chama a atenção para algumas diferenciações entre os dois campos. Uma delas está no fato de que a realidade com que a história se preocupa é a do passado, enquanto que a realidade que está sendo objetivada no jornalismo é a do presente. E quando o presente vira passado? É justamente nesse ponto que o jornalismo se torna documento histórico como fonte de pesquisa. $\mathrm{O}$ mesmo ocorre com as narrativas jornalísticas de viagem.

Ainda é valoroso mencionar que as narrativas jornalísticas de viagem se diferem de obras ficcionais em que os seus personagens viajam, como por exemplo, no clássico Dom Quixote de Miguel de Cervantes. Assim como na História, o texto, para ser considerado jornalístico, deve se referir ao real, ao verdadeiro, ao que aconteceu. Sobre normas jornalísticas, destaca-se que: "uma norma implícita, e sempre presente no ato de fala, é o princípio da veracidade" (GOMES, 2011, p.9). Claro que nada impede que se utilizem técnicas da literatura para abordar acontecimentos reais, bem como a criação de cenas ou personagens ficcionais que possam ser devidamente identificados pelo leitor como um ato de criação literária.

Não menos importante é ressaltar que neste artigo, considera-se jornalismo literário de viagem apenas obras que apresentam o trânsito do jornalismo em primeiro ou segundo planos, ou seja, não estão incluídas obras em que o jornalista viaja para apurar as informações e entrevistar fontes e que não menciona tal viagem durante a narrativa, como foi o caso do clássico A Sangue Frio, em que o jornalista norte-americano Truman Capote viaja para o interior do Kansas para reconstruir a chacina da família Clutter cometida por dois assaltantes. Nesse caso, a história do crime é narrada mas sem mencionar no romance-reportagem a viagem feita pelo jornalista, que pode ser encontrada em prefácios e posfácios de diversas 
edições. Alguns exemplos de obras que apresentam a viagem em primeiro ou segundo plano da narrativa serão comentadas durante a análise do mapeamento feito.

Vale ressaltar também que jornalismo literário de viagem apresenta perspectivas diferentes da ficção literária, como também não se restringe no que é visto cotidianamente na prática do jornalismo diário ou comercial, apesar de não se desprender do viés literário que intrinsecamente horizontaliza a disparidade do real com o que é fantasioso. Despertar o imaginário do leitor a partir da perspectiva dos seus sonhos, instigando a vontade que o ser humano tem de romper com suas limitações geográficas, sentir-se onipresente, conhecer o mundo e ao mesmo tempo interagir com seus elementos socioculturais caracterizam essa prática. Assim, o viajante pode comportar-se de uma maneira leve, fantasiosa, expansiva. É assim que a mente funciona quando se vê livre da rolha da rotina (MODERNELL, 2007). Relatos testemunhais são comuns dentro desta narrativa. Pode-se dizer que ela é um gênero que dialoga com o processo das interfaces da tríade literatura, realidade e imaginário.

"Diariamente, os veículos desprezam o acompanhamento de boas histórias" (BELO, 2006, p.14). Isso implica no processo de migração, como alternativa para que os jornalistas contem boas histórias através do relato de viagens, materializadas em livros. Esse gênero permite que o escritor não apenas narre, mas que compartilhe experiências vividas com seus leitores. Além disso, não se pode negar as evidências dessa prática narrativa desde os primórdios da humanidade, como as que são trazidas na Bíblia:

\begin{abstract}
Desde os textos bíblicos, incluindo o Antigo Testamento, as narrativas de viagem se fazem presentes na literatura universal. De Moisés cruzando o Mar Vermelho, às epopeias de Homero, há personagens que viajam por cidades, países e, anos mais tarde, continentes. De Marco Polo a Pero Lopes de Sousa, de Erico Verissimo ao contemporâneo Airton Ortiz (RITTER, 2016b, p.166).
\end{abstract}

$\mathrm{Na}$ percepção do jornalismo literário de viagem, se o jornalista tem a escrita e o domínio das palavras como suas principais armas, o jornalista que opta por escrever e descrever suas experiências como viajante, além da escrita e das palavras, é, também, possuidor das emoções afloradas no psíquico, ocasionadas pelas fragmentações físicas sofridas com as alterações geográficas - elementos histórico-cultural - registradas por meio do seu escrever, ou seja, eternizadas em sua obra. Contar suas experiências ou testemunhar sobre o que presenciou pode ser considerada uma ótica unilateral, ou seja, a visão do jornalista resultaria na superficialidade de seu trabalho. Porém, quando o jornalista traz para primeiro plano o seu testemunho, acrescentado de depoimentos de terceiros, entrevistados, personagens 
em si, que dialogam e retratam o ambiente que está sendo narrado e como foi constituído, fatores quase sempre não notados pelo leitor e até para o jornalista - quem escreve, registra-se a heterogeneidade discursiva. Daí, então, pode ser percebida a importância e como vem sendo construído o jornalismo literário de viagem.

Em sua tese de doutorado, Mordernell (2009) problematiza a temática afirmando que: o jornalismo literário é também conhecido como novo jornalismo, literatura não-ficcional, literatura da realidade, jornalismo em profundidade, jornalismo diversional, reportagemensaio e jornalismo de autor. Ainda conforme o autor, termos esses que foram utilizados por escritores pioneiros na prática do jornalismo literário de viagem, nos Estados Unidos, como Tom Wolf, Gay Talese e Hunter S. Thompson, nos anos 1960/70.

Feitas essas breves considerações sobre jornalismo literário e sobre essa prática jornalístico-literária que tem a temática em primeiro ou segundo planos, em seguida é apresentado o mapeamento realizado. Paralelamente a isso, são feitas as inferências desenvolvidas a partir dos dados coletados.

\section{JORNALISMO LITERÁRIO DE VIAGEM INTERNACIONAL: CENÁRIO DE AUTORIAS BRASILEIRAS}

Uma coletânea de crônicas, de reportagens ou um romance de não ficção tendo como fundo uma ou mais viagens para outros países. Deslocamentos de tem, de carro, de ônibus, de navio ou de avião para os países dos cinco continentes descritos, narrados ou comentados por um ou mais autores. É numerosa a quantidade de estilos e formatos diferenciados dos livros contendo narrativas de viagens escritas por jornalistas brasileiros para abordar viagens ao exterior. Entre o período de novembro de 2016 e março de 2017, através do projeto de extensão intitulado Jornalismo Literário de Viagem: Narrativas de Jornalistas Transitando pelo Mundo, os autores do presente artigo identificaram 99 obras escritas por jornalistas brasileiros ou livros de autores estrangeiros traduzidas para o português que foram divididas em cinco grandes categorias: 1) jornalistas brasileiros narrando viagens para o exterior; 2) jornalistas brasileiros narrando viagens dentro do Brasil; 3) jornalistas estrangeiros abordando viagens ao exterior; 4) jornalistas estrangeiros tratando de viagens dentro de seus países de origem; e 5) narrativas de guerra, tanto de jornalistas brasileiros quanto estrangeiros.

Como essa é uma etapa inicial desenvolvida pelos integrantes do projeto, acredita-se que a lista deva ser bem mais ampla, no entanto, uma categoria se destaca pela grande 
quantidade de obras publicadas nos mais diversos tempos: a de jornalistas brasileiros em viagem ao exterior. No total, foram encontradas 60 obras de 35 autores que se enquadram nessa categoria, tendo as suas viagens aparecendo em primeiro ou segundo plano. Para tal identificação, foram consultados sites de editoras, portais de bibliotecas de universidades onde é oferecido o curso de Jornalismo e entrevistas à professores e escritores. O quadro abaixo ilustra o resultado dessa etapa da pesquisa. Vale ressaltar que o ano citado no quadro não é referente ao ano da primeira publicação, mas sim, ao ano da edição consultada ou encontrada nos sites das bibliotecas. 


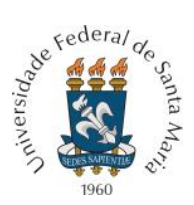

PROGRAMA DE PÓS-GRADUAÇÃO EM COMUNICAÇÃO DA UNIVERSIDADE FEDERAL DE SANTA MARIA

\begin{tabular}{|c|c|c|c|c|}
\hline Categoria & Nacionalidade do Autor & Nome do Autor & Nome da Obra & Ano \\
\hline $\begin{array}{c}\text { Viagens } \\
\text { Internacionais }\end{array}$ & Brasileiro/a & Adriana Carranca & O Afeganistão depois do Talibã & 2011 \\
\hline & & Adriana Carranca e Adriana Camargos & O Irã sob o chador & 2010 \\
\hline & & Adriana Mabilia & Viagem à Palestina & 2013 \\
\hline & & Airton Ortiz & Nova York & 2015 \\
\hline & & & Londres & 2016 \\
\hline & & & Atenas & 2013 \\
\hline & & & Paris & 2014 \\
\hline & & & Aventura no topo da áfrica & 1999 \\
\hline & & & Na trilha da Humanidade & 2006 \\
\hline & & & Egito dos Faraós & 2005 \\
\hline & & & Expedições Urbanas: Havana & 2010 \\
\hline & & & Expedições Urbanas: Jerusalém & 2011 \\
\hline & & & Na estrada do Everest & 2015 \\
\hline & & & Pelos caminhos do Tibete & 2001 \\
\hline & & & Cruzando a última fronteira & 2002 \\
\hline & & & Cartas do Everest & 2008 \\
\hline & & & A travessia da Amazônia & 2004 \\
\hline & & & Expresso para a Índia & 2009 \\
\hline & & & Vietnã pós guerra & 2009 \\
\hline & & & Gringo & 2009 \\
\hline & & & Em busca do mundo Maia & 2007 \\
\hline & & Airton Ortiz e Carlos Urbim & Aqui dentro a um longe imenso & 2010 \\
\hline & & Arthur Veríssimo & Gonzo! & 2014 \\
\hline & & Caco Barcellos & Nicarágua: A revolução das crianças & 1982 \\
\hline & & Carlos Augusto Leuba Salum & União Soviética hoje & 1987 \\
\hline & & Clovis Rossi & 25 anos ao redor do mundo & 1999 \\
\hline & & David Coimbra & Um trem para a Suíça & 2011 \\
\hline & & David Coimbra e Fernando Eichenberg & Viagem à palestina & 2001 \\
\hline & & Dodô Azevedo & Fé na estrada & 2012 \\
\hline & & Eduardo Scolese e Leonencio Nossa & Viagem com o presidente & 2007 \\
\hline & & Edvaldo Pereira Lima & Colômbia: Espelho América 26 & 2013 \\
\hline & & Eric Nepomuceno & Cuba: Anotações sobre uma revolução & 1981 \\
\hline & & & Nicarágua: Um país acossado & 1985 \\
\hline & & Erico Verissimo & A volta do gato preto & 1996 \\
\hline & & & Gato preto em campo de neve & 1996 \\
\hline & & & Israel em abril & 1996 \\
\hline & & & México & 1978 \\
\hline & & Ernesto Paglia & O diário de bordo do JN no ar & 2011 \\
\hline & & Fernando Morais & A ilha: um repórter brasileiro no país de Fidel Castro & 2001 \\
\hline & & Fernando Scheller & Paquistão, viagem à terra dos puros & 2010 \\
\hline & & Flávio Alcaraz Gomes & Um repórter na China & 1976 \\
\hline & & & Morrer por Israel & 1967 \\
\hline & & & Eu vi: itinerários de um repórter & 2007 \\
\hline & & Guilherme Soares Dias & Dias pela Estrada & 2017 \\
\hline & & Hermano Henning & Via satélite: histórias de um correspondente Internacional & 1996 \\
\hline & & Juremir Machado & Um escritor no fim do mundo & 2011 \\
\hline & & Luis Kawaguti & A República Negra & 2006 \\
\hline & & Marcelo Abreu & Viva o grande lider! & 2002 \\
\hline & & Marcelo Antônio Rech & Enviado especial: Passageiro da história & 1997 \\
\hline & & Martha Medeiros & Um lugar na janela: relatos de viagem & 2012 \\
\hline & & & Um lugar na janela: relatos de viagem 2 & 2016 \\
\hline & & Nestor de Holanda & O mundo vermelho & 1961 \\
\hline & & Paulo Ramos Derengoski & Viagens de um repórter & 2002 \\
\hline & & Pedro Bial & Crônicas de um repórter & 1996 \\
\hline & & & Leste Europeu, a Revolução ao vivo & 1990 \\
\hline & & Pedro Ernesto Denardin & 10 copas: "é demais" & 2011 \\
\hline & & Rodrigo Alvarez & No país de Obama & 2009 \\
\hline & & & Haiti, depois do inferno & 2010 \\
\hline & & Sônia Bridi & Laowai & 2008 \\
\hline & & Zeca Camargo & A fantástica volta ao mundo & 2004 \\
\hline & & Total de autores: 35 & Total de Obras: 60 & \\
\hline
\end{tabular}

Fonte: produção do autor 
Acrescenta-se que não estão listadas narrativas de jornalistas em viagem dentro do território nacional, de jornalistas estrangeiros ou de narrativas que tenham a temática guerra em primeiro plano. No entanto, em alguns casos há narrativas de correspondentes de guerra, mas não no sentido de narrar o conflito, e sim de descrever as comunidades que estão envolvidas nos conflitos, como é o caso, por exemplo, de O Afeganistão depois do Talibã, publicado pela jornalista Adriana Carranca.

Para elaboração do levantamento, também foram definidos três tipos de narrativas que resultam de viagens feitas pelo jornalista:

1) As narrativas com a viagem em primeiro plano: são aquelas em que a viagem é o tema da obra, em que a narrativa gira em torno da viagem. É a que aparece mais frequentemente na lista. Um exemplo é a obra Dias pela estrada, do jornalista Guilherme Soares Dias. "Não importa a distância do trajeto, a viagem será sempre tão grandiosa quanto a cabeça de uma criança pode imaginar" (DIAS, 2017, p.72). Outro especialista em escrever esse tipo de narrativa é o jornalista gaúcho Airton Ortiz, que já publicou 18 relatos de viagem, tendo em todos a temática em primeiro plano. Em Nova York, por exemplo, ele começa apresentando uma descrição da cidade. "Tudo começou aqui. E o começo não poderia ser mais american way of life. Nova York é a capital dos arranha-céus, mas também das áreas verdes. Parece contradição. Parece, mas não é” (ORTIZ, 2015, p.11). Ortiz e Dias são dois exemplos de jornalistas que abandonaram o trabalho das redações para se dedicar exclusivamente à produção de narrativas de viagem.

2) As narrativas com viagem em segundo plano. É aquela em que o jornalista viaja, deixa claro que está em trânsito, mas tem como foco principal outro assunto, que não a viagem em si. Um dos exemplos mais claros desse tipo de narrativa é o clássico A luta, do jornalista norte-americano Norman Mailer. Nessa obra, Mailer viaja para o Zaire (atual Congo, no continente africano) para cobrir a luta de boxe entre Muhammad Ali e George Forman, apontada até hoje como a maior luta do século XX. Mesmo tendo a luta como assunto principal da obra, o jornalista narra a viagem feita para o continente africano e descreve a cultura local em determinados trechos do livro: "Na presença de uma mulher vestida ricamente, um africano pode fazer mais do que saudar o aumento de poder de que a mulher é investida por sua túnica elaborada" (MAILER, 2011, p.39). Já dentre as obras brasileiras, Nicarágua: A revolução das 
crianças, de Caco Barcellos, e O Irã sob o chador, de Adriana Carranca e Adriana Camargo, podem ser classificadas nesta categoria.

3) Narrativas em que a viagem praticamente não é mencionada ou não é citada. É o exemplo do clássico A sangue frio, de Truman Capote, em que ele viaja para o interior do Kansas, nos Estados Unidos, para reconstituir a chacina cometida contra a família Clutter, no final dos anos 1950. Já um exemplo brasileiro desse tipo de produção é Os últimos soldados da guerra fria, de Fernando Morais. Mesmo tendo viajado para Cuba e outros países para contar a história dos espiões cubanos presos nos Estados Unidos, o jornalista não aparece no enredo, que apresenta as mesmas características narrativas do romance de não-ficção de Capote. Essa é a única das três categorias que não consta na lista, pois não se caracterizam por serem narrativas de viagem, simplesmente porque a viagem fez parte do processo de produção da obra mas não aparece na história contada.

Nesse momento da pesquisa, também não houve distinção em relação a produção temporal, pois estão incluídos desde autores contemporâneos, como Guilherme Soares Dias, que publicou a sua obra em 2017, e escritores do início do século XX, como Erico Verissimo (1905-1975), que atuou como jornalista e que publicou quatro narrativas de viagem: Gato preto em campo de neve, A volta do gato preto, México e Israel em abril. Nesta última obra, o escritor e jornalista deixa claro o seu gosto pela viagem: "Sou um insaciável devorador ou, melhor, degustador de cidades e paisagens. (Esse meu apetite no plano humano às vezes chega a ser quase antropofágico)"(VERISSIMO, 1997, p.15).

Outro tipo de obra que se destaca são as coletâneas. Em Gonzo!, Arthur Veríssimo apresenta 30 reportagens escritas a partir de viagens e publicadas na revista Trip. Nelas, mesmo sem apresentar as características do jornalismo gonzo de Hunter Thompson, Verissimo descreve os lugares e conta histórias inusitadas vividas longe do país. Numa delas, o jornalista vai ao Camboja, na Ásia. No texto, ele comenta o turismo de guerra oferecido pelos nativos, que cobram para que os turistas experimentem algumas de suas armas. “Quando entrei no 'almoxarifado' do tal campo de tiro e, entre outros bricabreques, vi a AK47 na prateleira, fui direto nela - foi a primeira da sessão" (VERÍSSIMO, 2014, p.95).

Os jornalistas David Coimbra e Fernando Eichenberg, no entanto, publicaram uma coletânea com crônicas escritas para o jornal Zero Hora, de Porto Alegre. Enquanto na primeira metade do livro aparecem os textos às vezes humorísticos, característico de David Coimbra, na parte final há o tom dramático de Eichenberg. A diferença no estilo dos dois 
jornalistas pode ser rapidamente percebida se analisarmos alguns breves trechos. No texto sobre a Itália, de David Coimbra, o autor descreve a seguinte cena: "A italiana maravilhosa agora dançava com os braços para cima. Se tem uma coisa que me enlouquece é quando as mulheres dançam com os braços para cima" (COIMBRA; EICHENBERG, 2001, p.12). Enquanto que no texto de Eichenbeg sobre a Macedônia o jornalista narra o drama dos refugiados: "O choro de um bebê se destaca num dos quatro ônibus estacionados, recémchegados da fronteira. É uma nova leva de refugiados” (COIMBRA; EICHENBERG, 2001, p.112).

Já outros autores apresentam viagens que buscam resgatar ou desvendar culturas ou pessoas. O jornalista Dodô Azevedo escreveu Fé na Estrada após viajar para os Estados Unidos para conferir o que restou da cultura beat e da obra de Jack Keouac no século XXI, pós os atentados de 11 de setembro de 2001. Para tanto, ele repetiu o trajeto feito pelo escritor norte-americano Jack Kerouac nos anos 1950, que tem como centro a famosa Rota-66. Aliás, sobre ela o autor comenta:

A estrada não é mais deserta a essa altura. Há lojas de souvenir onde você pode comprar chaveiros, isqueiros com o nome da estrada, ou bandanas de motociclista, ou óculos de motociclista, ou botas de motociclista, ou um motociclista feito de cera em tamanho real. Você também pode comprar calotas de carros antigos e placas de carro de todos os estados americanos (AZEVEDO, 2012, p.222).

Juremir Machado da Silva, por sua vez, busca desvendar o que há por trás do escritor francês Michel Houellebecq, guiando-o em uma viagem para a Patagônia. De tal experiência surgiu o livro Um Escritor no Fim do Mundo. Em formato de diário, ele conta como foi a viagem e os passeios realizados no sul da Argentina. "O comandante da embarcação não parava de falar em espanhol e inglês. Dava explicações turísticas, históricas, científicas, anunciava os serviços e os nomes dos integrantes da sua equipe [...]” (SILVA, 2011, p.154).

Como é possível de se perceber, nessa análise ainda breve e inicial do mapeamento feito de obras contendo narrativas de viagem de jornalistas brasileiros ao redor do mundo, são várias as possibilidades de estilos e formatos dos textos. Esse é apenas o pontapé inicial de outros estudos mais amplos e mais profundos sobre essa temática que fascina autores e leitores e que ainda foi pouco explorada pelos pesquisadores da área do Jornalismo em território nacional. 


\section{CONSIDERAÇÕES FINAIS}

Em viagens para a China, Itália, Alemanha, Argentina, Estados Unidos, África do Sul, Madagascar, Coréia do Sul ou do Norte ou para qualquer outra parte do Ocidente ou do Oriente, ou até mesmo para regiões inabitadas por seres humanos, os relatos feitos por jornalistas seguem sendo produzidos e publicados anualmente. Fazer um resgate das obras de jornalismo literário de viagens que já estão lançadas há pouco ou muito tempo e acompanhar as produções futuras ou em andamento são alguns dos objetivos do projeto de pesquisa Jornalismo Literário de Viagem: Narrativas de Jornalistas Transitando pelo Mundo, coordenado pelo autor deste artigo. Assim, o mapeamento e as breves considerações sobre as obras que se caracterizam por serem jornalismo literário de viagem, produzidas por jornalistas brasileiros em viagens ao exterior e apresentadas aqui, foi uma etapa importante no desenvolvimento da pesquisa sobre a temática.

Ressalta-se que para uma melhor compreensão do tema sempre é bom discutirmos os conceitos sobre o que jornalismo literário, feitos incialmente. Igualmente importante é o lançamento de uma discussão em torno, não só da terminologia, mas também da conceituação do que aqui foi chamado de jornalismo literário de viagem. Apenas com a colaboração dos pesquisadores da área é que poderemos balizar melhor os elementos que guiarão futuros pesquisadores sobre a temática. A análise mais aprofundada de mais obras, não só apenas da categoria abordada aqui como das demais, em estudos posteriores serão fundamentais para compreender as peculiaridades e importância desse gênero.

Outro ponto importante de ser lembrado é que esse é um trabalho contínuo. Outras obras não identificadas nesse momento pelos pesquisadores podem ser agregadas à lista apresentada, bem como futuros lançamentos. Cita-se como exemplo o livo de Dias (2017) que foi lançado paralelamente ao levantamento que estava sendo feito pelos pesquisadores. Também há futuros desafios, como ampliar o mapeamento de obras de jornalismo literário de viagem feitas por jornalistas estrangeiros que tenham seus livros publicados no Brasil em língua portuguesa. Já as narrativas de guerra, que nesse momento não são foco do projeto de pesquisa, podem ganhar mais espaço futuramente com a adesão de novos pesquisadores ao grupo.

Feitas essas considerações, encerra-se essa etapa da pesquisa salientando que foi possível, através desse estudo, observar o produto dessa relação íntima entre o Jornalismo e a Literatura, produto esse que possui evidências de sua existência desde os primórdios da 
humanidade, conforme visto anteriormente, e que tem sido cada vez mais elaborado por jornalistas que desejam se desapegar da estrutura engessada da pirâmide invertida, das rotinas do jornalismo diário e que desejam contar de forma mais humanizada e subjetiva as histórias e experiências vivenciadas ao longo de sua carreira. Inclusive as viagens, que fascinam e encantam a tanta gente. Proporcionalmente instigador é o desejo em seguir acompanhando essas trajetóias, não só para enriquecer as discussões que existem sobre a temática na área, como também para se registrar esse conjunto de obras tão importantes para a história do jornalismo brasileiro e internacional.

\section{REFERÊNCIAS}

AZEVEDO, D. Fé na estrada - seguindo os passos de Jack Kerouac. Rio de Janeiro: Casa da Palavra, 2012.

BARDIN, L. Análise de conteúdo. São Paulo: Edições 70, 2011.

BELO, E. Livro-reportagem. São Paulo: Contexto, 2006.

BENEDETI, C. A. A qualidade da informação jornalística - Do conceito à prática. Florianópolis: Insular, 2009.

BORGES, R. Jornalismo literário - teoria e análise. Florianópolis: Insular, 2013.

BOYNTON, R. S. The new new journalism - Conversation with America's best nonfiction on their craft. New York: Random House, 2005.

BULHÕES, M. Jornalismo e literatura em convergência. São Paulo: Ática, 2007.

COIMBRA, D.; EICHENBERG, F. Viagem. Porto Alegre: Artes e Ofícios, 2001.

COSON, R. Romance-reportagem: o gênero. Brasília: Editora Universidade de Brasília. São Paulo: Imprensa Oficial do Estado, 2001.

DIAS, G.S. Dias pela estrada - cenas de uma vida e de um mundo em movimento. Rio de Janeiro: Multifoco, 2017.

GOMES, W. Jornalismo, fatos e interesses - Ensaio de teoria do jornalismo. Florianópolis: Insular, 2009.

HERSCOVITZ, H. Análise do Conteúdo em Jornalismo. In: LAGO, Cláudia; BENETTI, Marcia (Org.). Metodologia de pesquisa em jornalismo. Petrópolis: Vozes, 2007.

LIMA, E. P. Páginas ampliadas. Barueri: Manole, 2004.

MAILER, N. A luta. São Paulo: Companhia das Letras, 2011.

MASINA, L. Guia de leitura: 100 autores que você precisa ler. Porto Alegre: LPM, 2009. 
MARTINEZ, M. Jornalismo literário - tradição e inovação. Florianópolis: Insular, 2016.

MONTORO, J. A. Periodismo y literatura. Madri: Guadarrama, 1973.

MODERNELL, R. Em Trânsito: um Estudo Sobre Narrativas de Viagem. São Paulo: Universidade Presbiteriana Mackenzie, 2009 (tese de doutorado).

MODERNELL, R. Narrativas de Viagem e Jornalismo Literário. São Paulo: Todas as Letras Revista de Língua e Literatura, volume 9, número 1, 2007.

PENA, F. Jornalismo literário. São Paulo: Contexto, 2006.

ORTIZ, A. Nova York. São Paulo: Saraiva, 2015.

RITTER, E. A tribo jornalística de Erico Verissimo. Ijuí: Unijuí, 2016a.

RITTER, E. Israel em abril: uma narrativa de viagem de Erico Verissimo na interseção entre jornalismo e literatura. Sorocaba: Revista Tríade, volume 4, número 8, $2016 \mathrm{~b}$.

SILVA, J.M. Um escritor no fim do mundo - viagem com Michel Houellebecq à Patagônia. São Paulo: Recod, 2011.

VERISSIMO, A. Gonzo! Santos: Realejo, 2014.

VERISSIMO, E. Israel em abril. São Paulo: Globo, 1997.

Original recebido em: 03 de agosto de 2017

Aceito para publicação em: 26 de janeiro de 2018

\section{Eduardo Ritter}

Professor Adjunto do Departamento de Ciências da Comunicação (Decom) da Universidade Federal de Santa Maria (UFSM), campus Frederico Westphalen. Doutorado em Comunicação Social pela Pontifícia Universidade Católica do Rio Grande do Sul (PUCRS) com bolsa Capes/PDSE na New York University (Nova Iorque, Estados Unidos). Atuou como jornalista em emissoras de rádio, jornais, assessoria de imprensa e agências de notícia do Rio Grande do Sul. É autor de A Tribo

Jornalística de Erico Verissimo (Unijuí, 2016) e Jornalismo Gonzo: Medo, Delírio, Mentiras Sinceras e Outras Verdades (Insular, 2018). 